\title{
Research and Compare Standards of E-Learning Management System: A Survey
}

\author{
Zeinab Shariat \\ Islamic Azad University of Boumehen, Tehran, Iran \\ E-mail: zshariat@alum.sharif.edu
}

\begin{abstract}
Seyyed Mohsen Hashemi
Dean of the Software Engineering \& Artificial Intelligence Dept., Science \& Research Branch, Islamic Azad University, Tehran, Iran

E-mail: Hashemi@isrp.com
\end{abstract}

\author{
Asad Mohammadi \\ Amir kabir University of Technology, Tehran, Iran \\ E-mail:ad.mohammadi@aut.ac.ir
}

\begin{abstract}
Nowadays, using of e-learning has a special place in organizations and universities. Understanding the efficiency and effectiveness of this type of education, scientific and professional assemblies try to provide effective tools and strategies to operate this kind of training better. E-Learning management system as one of the basic requirements of the system plays a special role in this field. Therefore all companies are looking for a system that meets their needs in the field of e-learning. Standards of content and structure of elearning must be set so that access to possibilities such as content reuse or gathering or discriminating subject from various sources at different times is possible. This paper reviews and compares some of the most important standards in the field of e-learning.
\end{abstract}

Index Terms - Learning Management Systems, Standard, SCORM, Meta Data and Interoperability, AICC, IEEE LTSC

\section{Introduction}

E-learning can be seen as a new approach to provide interactive learning environment with appropriate design that facilitates the learning and by use of different resources in various digital formats, makes learning at any time and any place possible for everyone[1]. Several levels have been for using suggested for using information technology in teaching and learning. The most simple is for communication (such as video conferences and remote classes) and other uses are: means to collect, to store and to present information, or use it as a cognitive tool, data mining tool, searching and interpreting information, and finally use of artificial intelligence towards intelligently matching process and learning content with trainees' needs and learning styles[2].
Alignment of technologies used in the products is extremely important for consumers, because when manufacturers follow the same standard for a product, the consumer encounter greater choice in buying a product. Furthermore, when a product is standard it means greater durability in the market and purchasing on behalf of the purchaser would be more logical. Standards have led assurance to invest in human resources and time. These standards could also provide transfer from one system to another one. In other words, they can provide full and appropriate use of purchased materials. Furthermore, creating a library of texts by use of Learning Management System with valid standards will decrease the risk of loss of investment in educational technologies[2,3,4].

In this paper, concepts of e-learning management system and the importance of standards in e-learning are reviewed. The second part of the paper presents the description of e-learning and the third chapter explains the need for standardization. In the fourth part, standard SCORM, Metadata and Interoperability, AICC, IEEE LTSC are described and compared.

\section{Introducing E-learning System}

E-learning Management Systems is a software that records, tracks and follows the activities of trainees. In other words, this system which is a common structure and foundation for many applications of e-learning, handles learning and training process automatically. A powerful and comprehensive learning management system facilitates performance management of learning programs, in an organization and helps employees and learners assess their training and plan their next steps for learning[1,4]. 
All learning management systems have the specifications and properties, but provide them in various forms and by different ways. Some of these systems provide supervision and management tools to their customers when learning operation begins; Some of these systems act as competence devices which help students choose courses based on training needs and some just offer a list of courses. In addition, these systems are variable according to the tastes and desires of customers. Some are provided to simulate classes and educational activities, 3D educational environments along with various shapes and some of them use only the writing tools and are simple. Some of them are visual and have media bandwidth receiver and some do not cover videos[1,2,3].

\section{Standardization in E-learning}

With the rapid advancement in the world of technology, standards are the most important factor for maintaining of quality, increasing confidence of clients, aligning parallel movements of universities and other science producing sources. Although standards in some areas limit to manufacturers and developers, but if necessary considerations are observed in creating and updating the standards then they will increase the speed and progress. With rapid development of Web-based elearning, presence of appropriate standards would seem necessary. Since the e-learning industry is growing day by day, some standards have been developed to coordinate them. It is necessary that those who are involved in e-learning become familiar with these standards and use them for editing training courses in order to develop the quality and efficiency of their products. Without observing these standards, the quality and efficiency would not be desirable and shifting of training courses from one system to another system would be impossible or difficult [2,6].

Specification is one of the most times in standards and that is a collection of documentary descriptions. Some of the features (Specs) are provided after processing and become standard. In some industries, no items can be sold without the governmental stamp of approval (As in the case of electrical equipment that IEEE approval is necessary)[5].

\subsection{Types of Standards}

Types of standards are as follows[2,3,4]:

- Standard de jure: this means a standard that has been approved by the law. This term is usually used in contrast to standard facto de. Examples are IEEE LTSC, ISO/IEC-JTC1/SC36 or CEN / ISSS that have received European approval.

- Standard de facto: means an entity, regardless of that this entity is legally a responsible from an organization or not. Normally, when a significant number of users accept a specification or adapt themselves to it, then it becomes standard de facto and examples are TCP / IP, VHS, HTTP and etc.

\section{Important Standards for E-Learning}

Because e-learning is a new concept, its standardization is not yet completed and currently only some organization or institution work on it. Some of these standards are introduced in this section.

\subsection{SCORM Standard}

SCORM $^{1}$ is a technical standard that was created and developed by ADL. This standard supports the following six key high-level requirements [7,8,9]:

1. Availability: Makes educational content available for remote locations.

2. Adaptability: Permits the orders to become adapted to each individuals and organizations.

3. Economic: Decreases the time and costs of delivery of the educational content.

4. Durability: Educational content should not have need to redesign, reprogramming or reconfiguration to be updated with technology evolution.

5. Interoperability: Educational content developed in one location with one set of tools can be used in another place with other tool sets.

6. Reusability: A part of the educational content can be used in several applications or texts.

SCORM is a collection of related documents. There are 3 main documents of SCORM and a review document. 3 main documents are[8,9]:

\section{Content aggregation model}

2. Runtime environment

3. Arrange and conduct

Arrange and conduct documents are the newest ones (introduced by SCORM 2004) and most likely will receive most changes. Content aggregation model and runtime environment are stable and new version of them will not be provided soon.

In fact, SCORM is a leveled set of fundamental properties and e-learning content standards, technologies and related services. Today, organizations providing these specifications and standards work with each other on the SCORM and plan for the future. SCORM specifications and standards have proven that

${ }^{1}$ Shareable Courseware Object Reference Model 
they are able to meet the requirements of interoperability, reusability and other requirements. It is also cleared that SCORM can be the foundation of learning technologies used by organizations in the future education environment. Continuing working on these standards ensures that higher volume of operational capabilities will be operated.

\subsection{Metadata and Interoperability Standards}

Educational technology in order to have economic benefits, must be associated and supported by metadata and interoperability standards. Metadata is information that is considered as identification of other information. In other words, metadata refers to brief information that is necessary for expressing the main information characteristics[10].

Subject listing cards, author, title and etc in libraries are suitable examples of metadata. In this card, book title, author, publisher, subject category and edition are written and these give information about a book. MIME is also a part of the standard metadata that is relating to information posted on the internet and informs receiver about information and software required to process it[11].

Interoperability means standards that provide different systems or different components of systems communicate with each other. Protocol such as IP (Internet Protocol) and standards like PS (Post Script) are examples. IP lets various systems exchange information. Documents, using the standard PS, can be used on any systems which are capable of matching with it and know the language of this format. In many cases, metadata standards will play a role of Interoperability standards.

Organizations such as IEEE LTSC, IMS, ADL, AICC and some other European groups are searching on these standards. Particularly, AICC is working on an independent and unique industry, ADL works on generalizing and IEEE LTSC are looking to create a formal standard[10,11].

\subsection{AICC Standard}

$\mathrm{AICC}^{2}$ standard was primarily formed on the need of standardizing of computer training for using in airline industry, but now, it is used for reusability, interoperability in online learning and applications such as health care, financial services, higher education and telecommunication. Currently, a large number of educational consortiums and valid standard groups have accepted AICC guidelines for their industries and follow them[12].

AICC recommendations are generalized about all computer-based training and include supplying,

\footnotetext{
${ }^{2}$ Aviation Industry CBT Committee
}

controlling, delivering and monitoring the results of management systems training and internet courses. One of the goals of AICC Institute is gaining maximum benefit from the educational investment and for this purpose, it seeks to promote standards of educational products that vendors can offer them to other industries. The Institute has coordinated it's activities with other organizations active in the field of educational technology standards such as IMS, IEEE LTSC, ADL, and now it is a de facto standard. In summary, AICC general objectives are[13]:

a) Assisting aircraft operators to complete and economical methods of computer-based training.

b) Completing guidelines to provide appropriate use of information exchange capabilities.

c) Creating an open-debate space on standards of computer-based education and other instructional technology.

AICC meetings will be held once every three years in North America and Europe will be formed. Usually one of the companies that is a number of AICC Guidelines \& Recommendations Union is hosts the meeting. In the meeting, three types of documents, including AICC guidelines and recommendations of AICC (AGR), technical reports and business documentation are provided. This section provides a brief description of each of these documents[6,12].

\section{AICC guidelines and recommendations}

All of these recommendations were approved by the official members and ware named with prefix AGR and a number. These documents are[12,13]:

AGR-001(AICC Publications): Includes a summary of AICC policies and recommendations, technical reports and articles.

AGR-002 (Courseware Delivery Station): This document contains recommendations for the use of computer education in the airline industry. Recommendations in this document are about the type of CPU, system speed, bus, graphics cards, displays, CD ROM, RAM, power supply, OS, mouse, keyboard, digital audio systems, and networks.

AGR-003 (Digital Audio): This document contains guidelines for developing and improving the quality of digital sound.

AGR-004 (OS): This document contains a formal recommendation to the airline industry about the type of operating system.

AGR-005 (Peripheral devices, computer training): This document provides guidelines to improve the performance of peripheral devices such as video cards.

AGR-006 (Computer managed instruction): This document recommends policies to enhance CMI 
systems capabilities that means creating the ability in CMI system to manage computer-based training which is provided by different sources. Furthermore, it also includes the ability to exchange information with different CMI systems.

AGR-007 (Exchange software course): This document provides a platform for the exchange of software course, such as text, graphics, moving images, sound and etc which are used in computer-based education.

AGR-008 (Digital Video): Policy document creation, distribution and use of digital video on computer software training course are presented in this document.

AGR-009 (User): This document includes instructions and guidelines for user tasks in the computer-based training.

AGR-010 (Web-based computer-managed instruction): The document recommends the policies for improving the ability of Web-based CMI systems.

\section{AICC reports and technical articles}

Articles and technical reports include different matter such as technical details of AGR. Each of these reports are marked with a special prefix which are[12,13]:

- CMI - Computer-Managed Instruction

- COM - Communications

- CRS - Courseware Technology

- EXC - Executive Committee

- ITL - Independent Test Lab

- MPD - Media and Peripheral Devices

- PLT - Platform

- WOS - Window \& Operating Systems

Each document in these reports has a three-digit prefix and documents usually are numbered in sequence.

\section{AICC working documents}

The third type of AICC documents are working documents. These public documents include the articles which are developed by the members of the subcommittees during their work period or during the time of preparation of the article[12].

\subsection{IEEE LTSC Standard}

We can name LTSC $^{3}$ as one of the best known IEEE standard and its most important characteristic is LOM.

\footnotetext{
${ }^{3}$ Learning Technology Standards
}

Copyright @ 2014 MECS
IEEE has made LTSC is responsible for developing technical standards and recommended practices, guidelines for implementing computer learning, components and training systems (especially software components, tools, technologies and design techniques that make development and maintenance possible)[14]. Many of the standards developed by LTSC are used as international standards by the international organization for standardization of electronics. Technical and information Committee have been implemented for learning, education and training $[14,15,16]$.

The standard represents a high-level model of elearning system architecture. However, this standard does not describe details of implementation of specific technologies but rather reflects the goals of people activities, roles involved in e-learning, computerrelated processes and each required knowledge.

Generally, IEEE is going to standardize these five categories:

1. General items

2. Learn more about

3. Content

4. Data and metadata

5. Management systems and applications

\subsection{IMS Standard}

$\mathrm{IMS}^{4}$ project was begun as a national infrastructure of higher education in the United States. This project is managed by the union called EduCAUSE (which it is used to be called Educom) in forms of hundreds of universities and educational institutions. The project aims to establish standards for dealing with problems associated with the increasing use of new technologies in teaching and learning $[17,18,19]$.

In training and e-learning environment, interoperability is important. IMS standard provides following sections in this regard[18]:

- IMS Learning Resource Meta-Data Specification: Describes learning resources in order to search

- IMS Enterprise Specification: Is used for sharing data about learners, courses etc. in the existing applications and systems on different substrates

- IMS Content Packaging Specification: Creates and shares content objects, reusable learning content

- IMS Question \& Test Specification: Shares test items and other assessment tools

- IMS Learner Information Package Specification: Organizes information so that the learner can learn

Committee

${ }^{4}$ Instructional Management System 
the system for a specific user and can provide appropriate needed responses.

\section{- IMS Reusable Competency Definition} Specification: Is used for the descriptions, references and related transactions with key characteristics of a potential

- IMS Simple Sequencing Specification: Illustrates how learning is arranged and provided in a specific sequence for a learner.

- IMS Accessibility Specification: This section has been created to provide guidance and other sectors and it aims to ensure the availability and ease of use of other portions of the standard specification.
- IMS Learning Design Specification: This section is used to introduce the interaction scenarios for creator of subject and educational courses.

- IMS Digital Repositories Specification: Is used to integrate online learning system with other data sources.

\section{Comparing Standards}

In Table 5-1, the standards discussed in previous section are compared with each other.

Table 5-1: Comparison of E-Learning Standards

\begin{tabular}{|c|c|c|c|c|}
\hline Standard Name & Constructor & $\begin{array}{l}\text { Years of } \\
\text { Construct }\end{array}$ & Advantages and Features & Objective of Production \\
\hline SCORM & $\mathrm{ADL}^{5}$ & 1999 & $\begin{array}{l}\text { - Gathering and fundamental } \\
\text { features of several standard } \\
\text { eLearning } \\
\text { - Small and shareable content } \\
\text { - Interactive data content } \\
\text { - To transfer content to other } \\
\text { systems }\end{array}$ & $\begin{array}{l}\text { Provides a framework to describe } \\
\text { specific components and connections } \\
\text { between them in virtual education }\end{array}$ \\
\hline $\begin{array}{l}\text { Meta Data and } \\
\text { interoperability }\end{array}$ & $\begin{array}{l}\text { AICC , ADL } \\
\text { IMS , IEEE }\end{array}$ & 1998 & $\begin{array}{l}\text { - Economic } \\
\text { - Low volume } \\
\text { - Easy access for searchers }\end{array}$ & $\begin{array}{l}\text { With the goal of creating economic } \\
\text { benefits for Educational Technology }\end{array}$ \\
\hline AICC & AICC & 1998 & $\begin{array}{l}\text { Having recommendation to work } \\
\text { with the operating system and } \\
\text { hardware in eLearning }\end{array}$ & $\begin{array}{l}\text { - Assist aircraft operators } \\
\text { - Create free space and suitable } \\
\text { platform for exchange of information }\end{array}$ \\
\hline IEEE LTS & IEEE LTS & 1996 & $\begin{array}{l}\text { - Easy maintenance and upgrades } \\
\text { - Reuse in new applications } \\
\text { - Ease of access to issues } \\
\text { - Facilitate access to educational } \\
\text { products } \\
\text { - The interaction with the exit } \\
\text { software }\end{array}$ & $\begin{array}{l}\text { In order to develop technical standards } \\
\text { and policies, as well as items related to } \\
\text { Computer Training }\end{array}$ \\
\hline IMS & IMS, NIST & 1999 & $\begin{array}{l}\text { - Development discoveries and } \\
\text { innovation in e-learning } \\
\text { - Reusability of electronic courses } \\
\text { - Group participation in e-courses }\end{array}$ & $\begin{array}{l}\text { Cover all the capabilities of e-learning } \\
\text { software }\end{array}$ \\
\hline
\end{tabular}

\footnotetext{
${ }^{5}$ Advanced Distributed Learning Initiative
} 


\section{Conclusion}

According to the survey, use of standard for creating and using of e-learning and training systems is inevitable. Particularly with a view that in the future many applications will use the open source approach, the role of standards will be very important. Researches show that achieving to an educational standard is far away. However, the least advantage of applying standards is their guiding descriptor aspects which allow system manufacturers and electronic content suppliers provide faster and higher quality products and services. In this paper, important standards such as SCORM, Metadata, Interoperability, AICC, IEEE LTSC and IMS were described and compared. One of the main issues in the field of comparing the standards is their goals of being built. Since each e-learning system is composed of several components, goals of each standard can be different.

\section{References}

[1] William Horton"‘E-Learning by Design`" Copyright (C) 2006 by John Wiley \& Sons، Inc. Published by Pfeiffer an Imprint of Wiley 989 Market Street، San Francisco، CA 94103-1741.

[2] IEEE P1484.1/D8, 2001-04-06, "Draft Standard for Learning Technology", Learning Technology Systems Architecture (LTSA)

[3] Barritt, Chuck, "Reusable Learning Object Strategy", version 4.0, Cisco Systems, November 2001

[4] Paul Stacey, "E-Learning: Standards", March 2nd, 2001.

[5] Hodgins, Wayne and Conner, Marcia, "Everything you ever wanted to know about learning standards but were afraid to ask", Linezine, 2000.

[6] Fowler, John, "The Value of Open Standards in Higher Education Infrastructure" Sun Microsystems white paper

[7] SCORM Sharable Content Object Reference Model: SCORM 2004 2nd Edition Overview:@2004 Advanced Distributed Learning.

[8] ADL - (Advanced Distributed Learning Initiative), SCORM 2004 Overview. http://www.adlnet.org/screens/shares/dsp_displayf ile.cfm?fileid $=992$

[9] ADL - (Advanced Distributed Learning Initiative), About SCORM. www.adlnet.org/index.cfm?fuseaction=AboutSCO $\mathrm{RM}$

[10] Baca, M. Gill, T., Gilliland, A.J., \& Woodley, M.S. "Introduction to metadata: pathway to digital information", Online Edition 2.1. Glossary(2000).
[11] "Metadata Standards and Interoperability", http://www.jiscdigitalmedia.ac.uk/guide/metadatastandards-and-interoperability

[12] AICC (Aviation Industry Computer Based Training Committee). AICC FAQ. http://www.aicc.org/pages/aicc_faq.htm

[13] AICC (Aviation Industry Computer Based Training Committee) Types of AICC Publications. http://www.aicc.org/pages/aicc3.htm\#PUB1

[14] IEEE LTSC (Institute of Electrical and Electronics Engineers) IEEE LTSC. http://ltsc.ieee.org/

[15] IEEE LTSC (Institute of Electrical and Electronics Engineers) IEEE LTSC WG1: Architecture \& Reference Model. http://ltsc.ieee.org/wg1/

[16] IEEE LTSC (Institute of Electrical and Electronics Engineers) IEEE LTSC WG12: Learning Object Metadata. http://ltsc.ieee.org/wg12/

[17] "IMS Question and Test Interoperability Metadata and Usage Data v2.0"، http://www.imsglobal.org/question/qti_v2p0/imsqt i_mdudv2p0.html

[18] IMS Global Learning Consortium (In-structional Managements Systems Project). About IMS. http://www.imsproject.org/aboutims.cfm

[19] IMS Global Learning Consortium (In-structional Managements Systems Project) IMS Specifications. http://www.imsglobal.org/specifications.cfm

\section{Authors' Profiles}

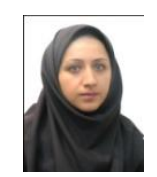

Zeinab Shariat: PHD student for computer science in Science \& Research Branch, Islamic Azad University, major in Ad hoc network and E-learning systems.

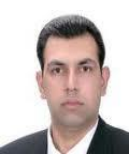

Seyyed Mohsen Hashemi: Ph.D. in Electronic Service and Software Engineering, Faculty Member of the Software Engineering and Artificial Intelligence Department, Assistant Professor, Computer Engineering Department Science and Research Branch, IAU University, interested in Software Intensive Systems, E-X systems (E-Commerce, E-Government, E-Business, and Virtual Banking.

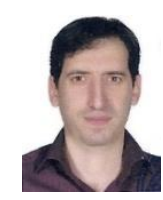

Asad Mohammadi: M.S. degree in Computer Science from Amirkabir University of Technology (Tehran Polytechnic University), major in Elearning systems 